\title{
MICROPALEONTOLOGIA E SEDIMENTOLOGIA APLICADAS À ANÁLISE PALEOAMBIENTAL: UM ESTUDO DE CASO EM CANANÉIA, SÃO PAULO, BRASIL
}

\author{
ROSA SETSUKO UEHARA, WÂNIA DULEBA, SETEMBRINO PETRI \\ Laboratório de Micropaleontologia, Instituto de Geociências, Universidade de São Paulo, Rua do Lago, 562, \\ 05508-080, São Paulo, SP, Brasil.waduleba@uol.com.br
}

MICHEL M. MAHIQUES \& MARCELO RODRIGUES

Departamento de Oceanografia Física, Química e Geológica, Instituto Oceanográfico, Universidade de São Paulo, Praça do Oceanográfico, 191, 05508-900,São Paulo, SP, Brasil.mahiques@usp.br

\begin{abstract}
RESUMO - Este trabalho teve por objetivo detectar variações ambientais que ocorreram durante os últimos 5000 anos em Arrozal, hoje um manguezal, situado ao sul do complexo estuarino lagunar de Cananéia-Iguape, São Paulo. Foram realizadas análises sedimentológicas e dos foraminíferos de 47 amostras, provenientes do testemunho AR4, de 4,32 m de comprimento. Entre 432 e $291 \mathrm{~cm}(5010$ e $4650 \pm 40$ anos AP), ocorrem sedimentos arenosos finos, ricos em diatomáceas, com baixas porcentagens de C, N, S e foraminíferos. Essa seqüência sedimentar arenosa provavelmente foi depositada durante o período regressivo ocorrido após a Transgressão Santos (5100 anos AP). No intervalo entre 291 e $173 \mathrm{~cm}$ (4650 e $860 \pm 40$ anos AP), as porcentagens de lama, C, N, S e foraminíferos aumentam. De 284 a $173 \mathrm{~cm}$ de profundidade, as espécies de foraminíferos são típicas de ambiente de plataforma marinha rasa, indicando influência marinha mais franca no local do testemunho. Uma hipótese plausível para a presença destes organismos marinhos seria que a ilha Comprida apresentaria dimensões menores que as atuais, pois estava sendo gradativamente formada de sul para norte. No intervalo entre 173 e $83 \mathrm{~cm}(860$ e $180 \pm 40$ anos AP), os foraminíferos calcários e aglutinantes mixohalinos tornam-se mais abundantes que os marinhos, indicando presença de ambiente estuarino. Durante esse período, supõe-se que parte da ilha Comprida já teria sido formada, agindo como anteparo natural à entrada do mar. Paralelamente, devem ter ocorrido períodos com maior pluviosidade, permitindo condições mixohalinas na região, visto que foram encontrados exemplares de Miliammina fusca. Finalmente, no intervalo de 83 a $12 \mathrm{~cm}$ (180 \pm 40 anos AP ao atual), os aglutinantes aumentam progressivamente rumo ao topo, sugerindo a formação do manguezal típico da região.
\end{abstract}

Palavras-chave: Foraminíferos, reconstituição paleoambiental, região estuarina-lagunar, análises granulométricas e geoquímicas, Holoceno.

ABSTRACT - MICROPALEONTOLOGY AND SEDIMENTOLOGY APPLIED TO ENVIRONMENTAL ANALYSIS: A STUDY CASE IN CANANÉIA, SÃO PAULO, BRAZIL. Analyses of sediment grain-size distribution, geochemistry and the foraminiferal content of 47 samples from a $4.32 \mathrm{~m}$ long core (AR4) were used to infer the environmental variations that occurred during the last five thousand years in the Arrozal region, near the southern end of the Cananéia-Iguape (SP) estuarine-lagoonal complex. From 4.32 to $2.91 \mathrm{~m}$ core depth interval (5010 to $4650 \pm 40$ years B.P.) sediments were finegrained sands with low percentages of $\mathrm{C}, \mathrm{N}$ and $\mathrm{S}$, but rich in diatoms with rare foraminifera occurrences. This sedimentary sequence was deposited during a regressive period, occurring after the Santos maximum transgression of 5100 years B.P. From $2.91 \mathrm{~m}$ to $1.73 \mathrm{~m}$ (4650 to $860 \pm 40$ years B.P) there was an increase in the percentage of mud, C, N and $\mathrm{S}$, and foraminifera. Within the interval between $2.84 \mathrm{~m}$ to $1.73 \mathrm{~m}$, there are marine platform foraminifera, indicating a strong marine influence in the Arrozal area at this time, probably as a result of the small size of the Comprida Island. From $1.73 \mathrm{~m}$ to $0.83 \mathrm{~m}$ ( 860 to $180 \pm 40$ years B.P.) a period of increased pluvial input and the northerly growth of the Comprida Island, acting as barrier against the sea, resulted in mixohaline conditions. These conditions were reflected in an increase of mixohaline calcareous foraminifera and agglutinated forms over marine species and the presence of brackish foraminifera (Miliammina fusca). Finally, from $0.83 \mathrm{~m}$ to $0.12 \mathrm{~m}$ (180 \pm 40 years B.P. to present) agglutinated forms increase upwards, coherent with the settling of the mangrove vegetation presently found in the region.

Key words: Foraminifera, paleoenvironmental reconstruction, estuarine-lagoon region, grain size and geochemical analyses, Holocene. 


\section{INTRODUÇÃO}

A evolução quaternária da planície costeira e dos canais lagunares de Cananéia-Iguape tem sido estudada por diversos autores (Petri \& Suguio 1971; Petri \& Suguio 1973; Suguio \& Petri, 1973; Suguio \& Martin, 1978; Martin \& Suguio, 1978; Suguio et al. 1985; Tessler, 1982; Tessler \& Furtado, 1983; Tessler \& Mahiques, 1993; Angulo \& Lessa, 1997; Angulo et al., 2006). Principalmente a partir dos dados sedimentológicos e radiométricos dos cinco primeiros trabalhos, foram estabelecidos os fundamentos básicos da estratigrafia regional, bem como elaborados o modelo de sedimentação e a curva de variação de nível do mar da região.

De acordo com o modelo e curva de Suguio et al. (1985), a sucessão de eventos quaternários seguiu a seqüência aqui descrita. Há 120000 anos ocorreu a transgressão Cananéia, em que o mar teria alcançado o atual sopé da serra do Mar. No decorrer desse evento, sedimentos argilo-arenosos, correspondentes à parte inferior da Formação Cananéia, foram depositados sobre a Formação Pariqüera-Açu. A sedimentação Cananéia foi completada com sedimentos arenosos marinhos. À fase transgressiva sucedeu-se uma fase regressiva que gerou vários cordões arenosos litorâneos correspondentes ao topo da Formação Cananéia. Durante esta fase o nível marinho esteve muito mais baixo que o atual.
Há 18000 anos, o nível do mar teria estado 140 m abaixo do nível atual, expondo os sedimentos anteriormente depositados. Os rios da planície costeira erodiram esses sedimentos, esculpindo canais, cujos remanescentes possuem alguma expressão batimétrica atual (profundidade média de $6 \mathrm{~m}$ ). No Holoceno, entre 6000 e 7000 anos A.P., a área foi palco de uma segunda transgressão, a transgressão Santos. O máximo desta transgressão teria ocorrido há 5100 anos, quando o nível do mar esteve cerca de $5 \mathrm{~m}$ acima do atual. Flutuações do nível marinho durante a parte final desta transgressão produziram várias gerações de cristas praiais, as quais podem ser observadas freqüentemente ao longo da ilha Comprida. Essa transgressão invadiu as áreas entalhadas pela erosão, estabelecendo um sistema deposicional lagunar. Nessas áreas rebaixadas foram depositados sedimentos areno-argilosos, ricos em material carbonoso. Já as partes mais elevadas da Formação Cananéia sofreram erosão, cujas areias foram redepositadas, formando depósitos holocênicos. Durante a subseqüente descida do nível marinho para o atual, novos cordões arenosos foram gerados.

Recentemente, surgiram algumas divergências de dados e controvérsias sobre as interpretações em relação à referida curva de variação do nível do mar (Angulo \& Lessa, 1997; Angulo et al., 2006). De acordo com estes autores, as oscilações de alta freqüência (200 a 300 anos) das curvas de

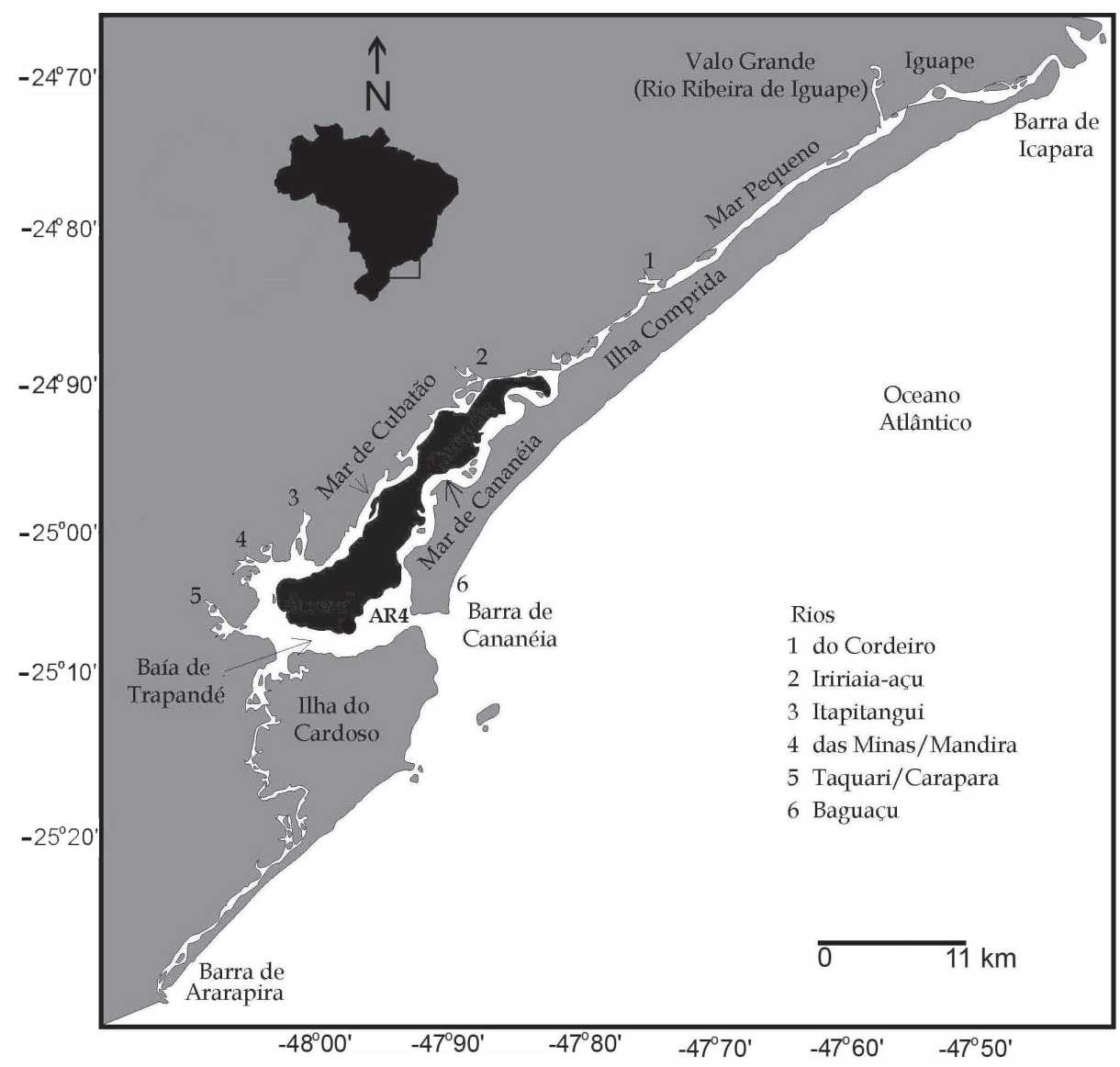

Figura 1. Mapa de localização do testemunho AR4, no sistema estuarino-lagunar de Cananéia-Iguape, SP, Brasil.

Figure 1. Location map of the AR4 core in the Cananéia-Iguape estuarine/lagoonal system, eastern Brazil. 


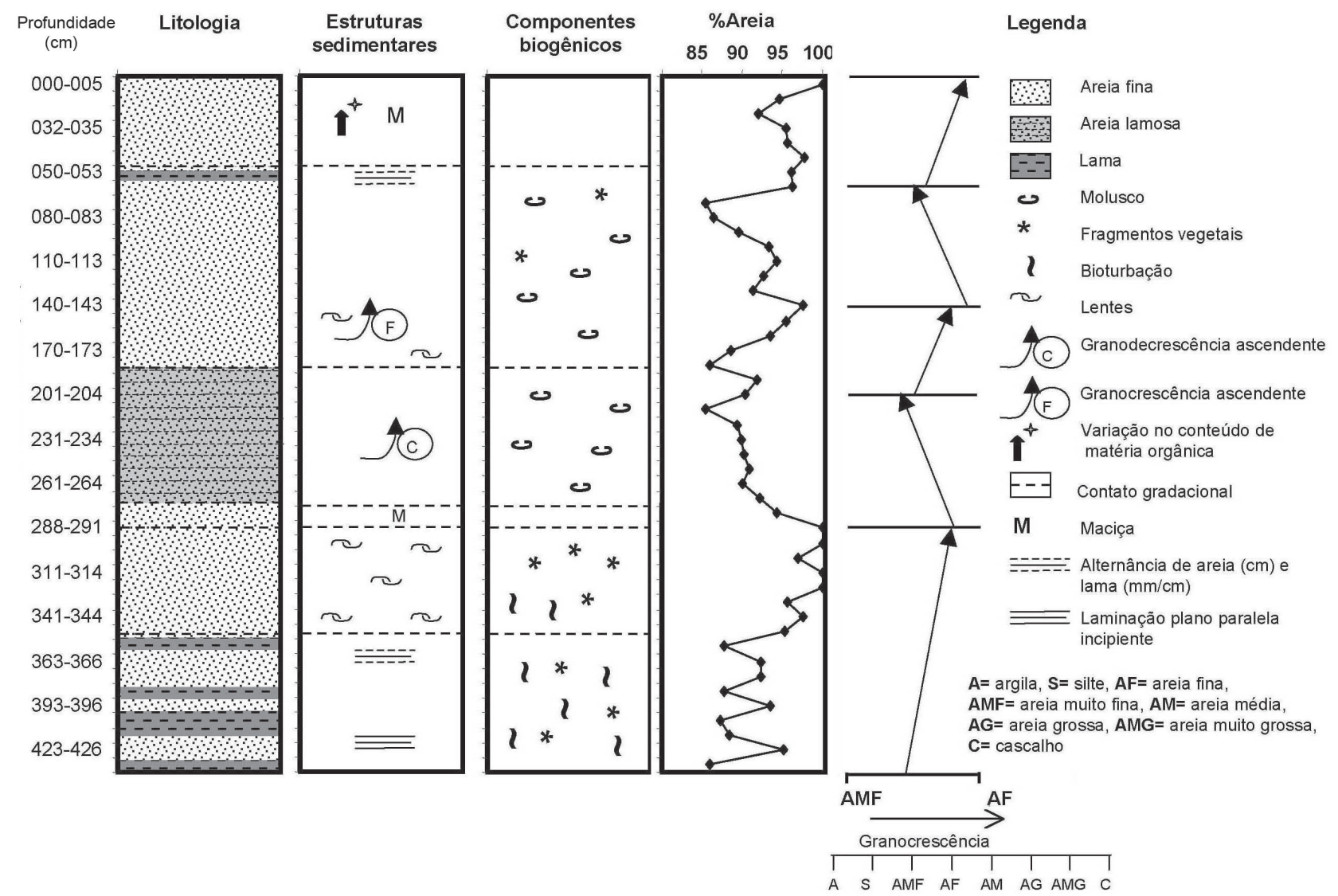

Figura 2. Litologias, estruturas sedimentares, componentes biogênicos, porcentagem de areia e padrões de granocrescência e granodecrescência ascendente do testemunho AR4.

Figure 2. Lithology, sedimentary structures, biogenic components, percentages of sand, coarsing or fining upward of the AR4 core.

Suguio et al. (1985) não teriam existido. Segundo Angulo \& Lessa (1987), após o nível máximo da Transgressão Santos (5100 anos A.P.), o mar teria descido progressivamente até atingir o nível atual, sem grandes oscilações. Apesar dessas controvérsias, ao se analisar a configuração média da curva proposta por Suguio \& Martin (1978), constata-se que o mar também teria descido progressivamente.

Em relação aos foraminíferos recentes, a região estuarinalagunar de Cananéia-Iguape (Figura 1) também já foi bastante estudada (Eichler \& Bonetti, 1995; Eichler et al., 1995; Bonetti, 1995; Eichler-Coelho et al., 1997; Debenay et al., 1998; Duleba, 1997). Contudo, estudos sobre foraminíferos sub-recentes e fósseis são raros nesta região (Petri \& Suguio,1971; Petri \& Lellis, 1971; Petri \& Suguio, 1973; Duleba, 1997). Particularmente a área do Arrozal, situada no Mar de Cananéia, ainda não foi estudada quanto aos microfósseis. Esse local é próximo à desembocadura de Cananéia e do único morro da ilha Comprida. Devido a estas peculiaridades, a região é potencialmente especial para se estudar o desenvolvimento da ilha Comprida, bem como as variações do nível do Mar, durante o Quaternário tardio.

Este trabalho tem por objetivo analisar a distribuição dos foraminíferos de sub-superfície e correlacioná-la com as características abióticas dos sedimentos recuperados de um testemunho de 4,32 m de comprimento. Discute-se as evidências das variações paleoambientais, desde 5010 anos AP até o presente e os resultados obtidos foram comparados às curvas de variação do nível do mar já existentes na literatura para a região (Suguio \& Martin, 1978; Angulo et al. 2006).

\section{ÁREA DE ESTUDO}

A configuração geográfica da região costeira do estado de São Paulo é o resultado de eventos geológicos de escalas distintas. Relaciona-se a possíveis fenômenos termais de reativações tectônicas da Plataforma Sul-Americana, ligados à abertura do Oceano Atlântico, ocorridos durante o Mesozóico-Cenozóico. Com a evolução do processo, desenvolveram-se falhas que condicionaram movimentos opostos de soerguimento da Serra do Mar e subsidência da Bacia de Santos (Almeida \& Carneiro, 1998). A partir do Terciário Superior e Pleistoceno, as flutuações do nível do mar, associadas às mudanças paleoclimáticas durante o Quaternário, foram as principais causas de formação, modelagem e evolução das planícies costeiras do Brasil. A sedimentação decorrente das sucessivas transgressões e regressões marinhas quaternárias é responsável pela maior parte do padrão de distribuição dos sedimentos na planície costeira paulista (Suguio \& Martin, 1978).

O litoral paulista está dividido em região norte e sul, sob 
Tabela 1. Dados granulométricos e parâmetros estatísticos de Wentworth (1922) do testemunho AR4. Abreviaturas: A, assimetria; BS, bem selecionado; MBS, muito bem selecionado; MS, moderadamente selecionado; P, profundidade; PS, pobremente selecionado.

Table 1. Grain size and Wentworth parmeters of the AR4 core. Abbreviations: A, asymmetry; BS, well sorted; MBS, very well sorted; MS, moderately sorted; P, depth; PS, poor sorted

\begin{tabular}{|c|c|c|c|c|c|c|c|c|c|c|}
\hline $\begin{array}{c}\mathbf{P} \\
(\mathrm{cm})\end{array}$ & $\begin{array}{c}\text { Areia } \\
(\%)\end{array}$ & $\begin{array}{c}\text { Lama } \\
(\%)\end{array}$ & $\begin{array}{c}\text { Silte } \\
(\%)\end{array}$ & $\begin{array}{c}\text { Argila } \\
(\%)\end{array}$ & $\begin{array}{c}\text { D. médio } \\
(\Phi)\end{array}$ & $\begin{array}{c}\text { Wentworth } \\
(1922)\end{array}$ & $\begin{array}{c}\text { G. seleção } \\
(\sigma)\end{array}$ & $\begin{array}{c}\text { Folk \&Ward } \\
(1957)\end{array}$ & A & Curtose \\
\hline $000-005$ & 100,0 & 0,0 & 0,0 & 0,0 & 2,74 & areia fina & 0,48 & MBS & $-0,01$ & 0,95 \\
\hline 012-015 & 94,7 & 5,4 & 4,9 & 0,4 & 2,86 & areia fina & 0,68 & MBS & 0,21 & 1,45 \\
\hline $022-025$ & 92,0 & 8,0 & 7,5 & 0,5 & 2,68 & areia fina & 0,92 & MS & 0,25 & 1,51 \\
\hline 032-035 & 95,4 & 4,7 & 4,2 & 0,5 & 2,74 & areia fina & 0,59 & MBS & 0,12 & 1,12 \\
\hline $042-045$ & 95,6 & 4,4 & 4,1 & 0,3 & 2,67 & areia fina & 0,59 & MBS & 0,13 & 1,14 \\
\hline $047-050$ & 97,6 & 2,4 & 2,4 & 0,0 & 2,57 & areia fina & 0,52 & MBS & 0,05 & 0,98 \\
\hline $050-053$ & 96,1 & 3,9 & 3,6 & 0,3 & 2,62 & areia fina & 0,58 & MBS & 0,11 & 1,11 \\
\hline 060-063 & 96,2 & 3,8 & 3,6 & 0,2 & 2,66 & areia fina & 0,56 & MBS & 0,11 & 1,1 \\
\hline $070-073$ & 85,3 & 14,7 & 14,1 & 0,6 & 2,84 & areia fina & 1,2 & PS & 0,18 & 1,33 \\
\hline 080-083 & 86,4 & 13,6 & 12,9 & 0,7 & 2,62 & areia fina & 1,3 & PS & 0,21 & 1,32 \\
\hline 090-093 & 89,5 & 10,5 & 9,9 & 0,6 & 2,75 & areia fina & 1,01 & PS & 0,25 & 1,45 \\
\hline $100-103$ & 93,2 & 6,8 & 6,3 & 0,4 & 2,7 & areia fina & 0,88 & MS & 0,21 & 1,44 \\
\hline $110-113$ & 94,2 & 6,2 & 5,8 & 0,4 & 2,65 & areia fina & 0,9 & MS & 0,11 & 1,6 \\
\hline $120-123$ & 92,6 & 7,4 & 7,0 & 0,5 & 2,72 & areia fina & 0,9 & MS & 0,23 & 1,5 \\
\hline $130-133$ & 91,3 & 8,7 & 8,3 & 0,4 & 2,74 & areia fina & 0,9 & MS & 0,24 & 1,43 \\
\hline $140-143$ & 97,5 & 2,5 & 2,5 & 0,0 & 2,58 & areia fina & 0,48 & BS & 0,05 & 1 \\
\hline $150-153$ & 95,4 & 4,6 & 4,2 & 0,4 & 2,76 & areia fina & 0,55 & MBS & 0,13 & 1,18 \\
\hline $160-163$ & 93,5 & 6,5 & 6,1 & 0,4 & 2,83 & areia fina & 0,79 & MS & 0,25 & 1,56 \\
\hline $170-173$ & 88,5 & 11,5 & 10,9 & 0,6 & 2,9 & areia fina & 0,96 & MS & 0,29 & 1,5 \\
\hline $178-181$ & 86,0 & 14,0 & 13,2 & 0,9 & 2,98 & areia fina & 1,05 & PS & 0,31 & 1,54 \\
\hline $191-194$ & 91,8 & 8,2 & 7,7 & 0,5 & 2,88 & areia fina & 0,85 & MS & 0,26 & 1,51 \\
\hline 201-204 & 90,4 & 9,6 & 9,0 & 0,6 & 2,83 & areia fina & 0,93 & MS & 0,28 & 1,56 \\
\hline $211-214$ & 85,4 & 14,7 & 13,8 & 0,8 & 3 & areia fina & 1,13 & PS & 0,21 & 1,64 \\
\hline $221-224$ & 89,3 & 10,7 & 10,1 & 0,6 & 2,94 & areia fina & 0,93 & MS & 0,27 & 1,52 \\
\hline $231-234$ & 89,8 & 9,9 & 9,3 & 0,6 & 2,83 & areia fina & 1,06 & PS & 0,16 & 1,65 \\
\hline $241-244$ & 90,1 & 9,9 & 9,2 & 0,7 & 2,79 & areia fina & 0,97 & MS & 0,27 & 1,53 \\
\hline $251-254$ & 90,9 & 9,1 & 8,6 & 0,5 & 2,7 & areia fina & 0,94 & MS & 0,26 & 1,49 \\
\hline $261-264$ & 90,1 & 9,9 & 9,4 & 0,6 & 2,79 & areia fina & 0,94 & MS & 0,27 & 1,5 \\
\hline $273-276$ & 92,2 & 7,8 & 7,5 & 0,3 & 2,64 & areia fina & 0,89 & MS & 0,25 & 1,45 \\
\hline $276-279$ & 94,2 & 5,8 & 5,5 & 0,3 & 2,58 & areia fina & 0,77 & MS & 0,24 & 1,5 \\
\hline 288-291 & 100,0 & 0,0 & 0,0 & 0,0 & 2,39 & areia fina & 0,4 & BS & 0 & 0,95 \\
\hline 291-294 & 100,0 & 0,0 & 0,0 & 0,0 & 2,4 & areia fina & 0,4 & BS & $-0,01$ & 0,95 \\
\hline $301-304$ & 96,9 & 3,1 & 3,1 & 0,0 & 2,47 & areia fina & 0,49 & BS & 0,08 & 1,04 \\
\hline $311-314$ & 100,0 & 0,0 & 0,0 & 0,0 & 2,4 & areia fina & 0,4 & BS & $-0,01$ & 0,95 \\
\hline $321-324$ & 100,0 & 0,0 & 0,0 & 0,0 & 2,48 & areia fina & 0,47 & BS & $-0,01$ & 0,93 \\
\hline $331-334$ & 95,6 & 4,4 & 4,2 & 0,2 & 2,43 & areia fina & 0,52 & MBS & 0,11 & 1,09 \\
\hline $341-344$ & 97,5 & 2,5 & 2,5 & 0,0 & 2,33 & areia fina & 0,49 & BS & 0,07 & 1,04 \\
\hline $350-353$ & 95,2 & 4,8 & 4,6 & 0,2 & 2,45 & areia fina & 0,6 & MBS & 0,16 & 1,24 \\
\hline $353-356$ & 87,7 & 12,3 & 11,6 & 0,7 & 2,93 & areia fina & 0,99 & MS & 0,32 & 1,56 \\
\hline $363-366$ & 92,3 & 7,7 & 7,4 & 0,3 & 2,61 & areia fina & 0,88 & MS & 0,26 & 1,48 \\
\hline $373-376$ & 92,3 & 7,7 & 7,5 & 0,3 & 2,45 & areia fina & 0,9 & MS & 0,26 & 1,4 \\
\hline $383-386$ & 87,7 & 12,3 & 11,8 & 0,4 & 2,68 & areia fina & 1,04 & PS & 0,31 & 1,33 \\
\hline 393-396 & 93,4 & 6,6 & 6,3 & 0,3 & 2,47 & areia fina & 0,83 & MS & 0,28 & 1,66 \\
\hline $403-406$ & 87,2 & 12,9 & 12,3 & 0,6 & 2,67 & areia fina & 1,12 & PS & 0,3 & 1,29 \\
\hline $413-416$ & 88,4 & 11,7 & 11,2 & 0,4 & 2,7 & areia fina & 1,03 & PS & 0,27 & 1,3 \\
\hline $423-426$ & 95,0 & 5,0 & 4,8 & 0,2 & 2,46 & areia fina & 0,67 & MS & 0,17 & 1,22 \\
\hline $429-432$ & 85,9 & 14,1 & 13,5 & 0,6 & 2,86 & areia fina & 1,06 & PS & 0,31 & 1,35 \\
\hline
\end{tabular}

o aspecto morfológico. Ao norte, o embasamento PréCambriano atinge o mar em quase toda a extensão, excetuando-se pequenas planícies formadas na sua parte interna por depósitos continentais. Ao sul, desenvolvem-se grandes planícies essencialmente formadas por depósitos marinhos ou flúvio-lagunares. Essas planícies são separadas entre si por pontões do embasamento Pré-Cambriano em contato com a mar.

A área estudada situa-se no sistema estuarino-lagunar de Cananéia-Iguape $\left(25^{\circ} 01^{\prime} \mathrm{S}, 47^{\circ} 55^{\prime} \mathrm{W}\right)$, entre a foz do 


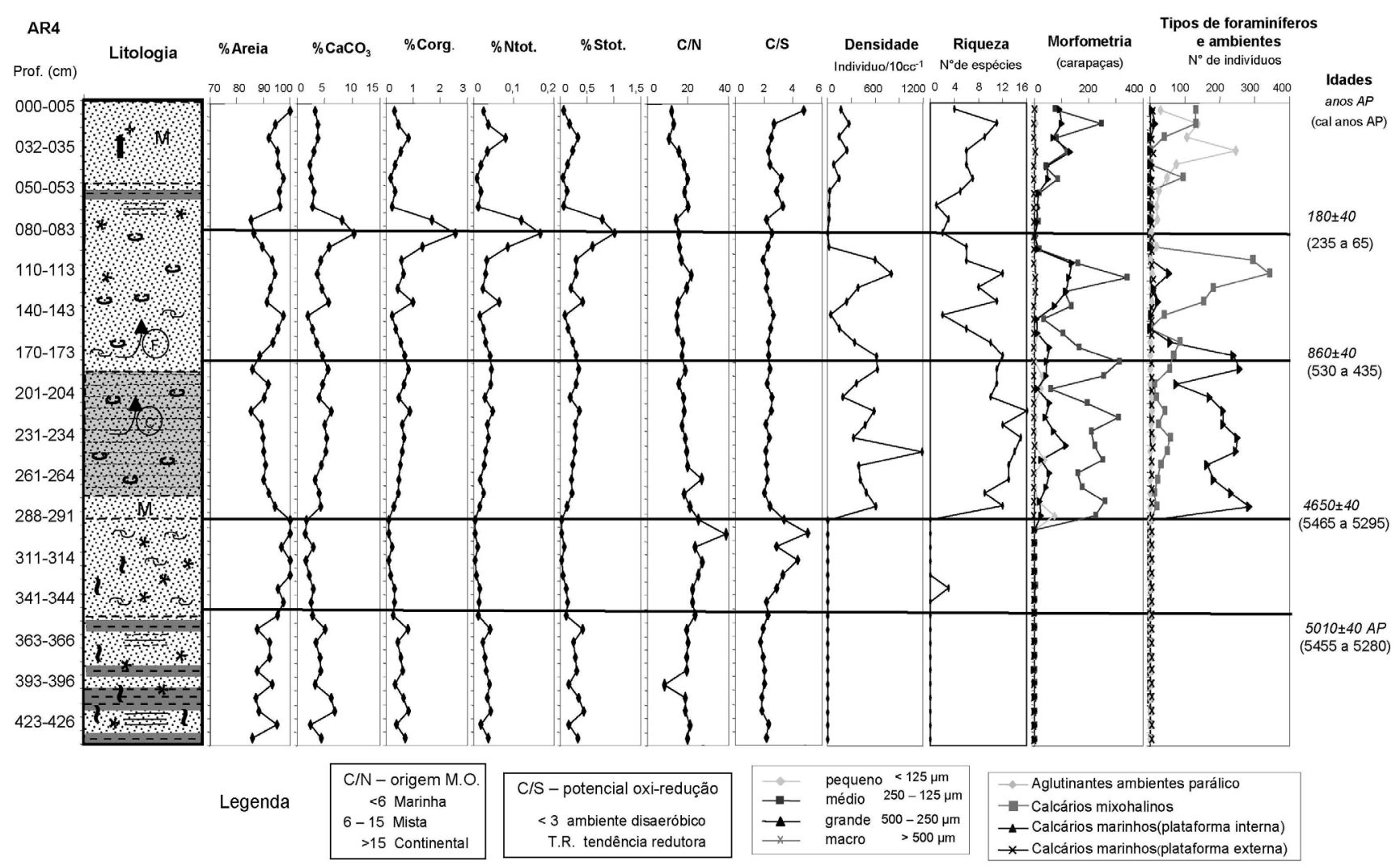

Figura 3. Resultados granulométricos, geoquímicos, microfaunísticos e radiométricos do testemunho AR4.

Figure 3. Grain size, geochemistry, microfaunal and radiometric results of the AR4 core.

rio Ribeira de Iguape e a divisa dos estados de São Paulo e Paraná. O sistema estuarino-lagunar de CananéiaIguape é formado por ambientes complexos, associados a ilhas-barreira, manguezais, bancos de lama e canais lagunares, cobrindo uma extensão de 130 por $40 \mathrm{~km}$ e é circundado por terreno Pré-cambriano (Figura 1).

\section{MATERIAL E MÉTODOS}

O testemunho analisado (AR4), do qual foram estudadas 47 amostras, foi coletado sob lâmina d'água de $0,50 \mathrm{~m}$ com testemunhador a vibração, em um banco de Spartina alterniflora, localmente denominado de Arrozal. Em laboratório, o testemunho foi aberto, fotografado, medido e descrito (cor, textura, estruturas sedimentares e componentes orgânicos). Fragmentos vegetais e conchas de moluscos foram coletados e datados por radiocarbono, pela técnica de MAS, e calibrados no laboratório Beta Analytic (EUA).Após a descrição e datação, o testemunho foi amostrado a cada 10 $\mathrm{cm}$, retirando-se $3 \mathrm{~cm}$ de sedimentos. De cada seção foram extraídas três subamostras, uma para análises granulométrica, geoquímica e do conteúdo microfaunístico.

As análises granulométricas foram executadas segundo os métodos de peneiramento e pipetagem descritos por Suguio (1973). Os teores de carbonato de cálcio foram obtidos por dissolução ácida em $\mathrm{HCl}$ a $10 \%$ e diferença de peso (Gross, 1971). As análises de carbono e nitrogênio foram realizadas no analisador LECO ${ }^{\circledR}$ CNS-2000 (Elemental carbon, nitrogen and sulphur analyzer).

Os dados granulométricos e os teores de carbonato biodetrítico foram classificados de acordo com Wentworth (1922) e Larssonneur et al. (1982), respectivamente. A partir dos resultados das análises de $\mathrm{C}, \mathrm{N}$ e $\mathrm{S}$ foi possível calcular as razões $\mathrm{C} / \mathrm{N}$ e $\mathrm{C} / \mathrm{S}$, que permitem fazer considerações sobre a origem da matéria orgânica (M.O.) e disponibilidade de oxigênio nos sedimentos, respectivamente. De acordo com Bader (1955), razões $\mathrm{C} / \mathrm{N}$ com valores abaixo de 6 indicam M.O. de origem marinha e acima de 15 de origem continental. Os valores intermediários indicam mistura de fontes marinha e continental. Os valores das razões $\mathrm{C} / \mathrm{S}$ acima de 3 indicam ambientes oxidantes, já baixos valores $(<3 \%)$ indicam ambientes redutores (Stein, 1991; Borrego et al., 1998).

De cada uma das 47 amostras foi retirada uma alíquota de $10 \mathrm{~cm}^{3}$, que foi peneirada a úmido em duas peneiras: 0,500 e $0,062 \mathrm{~mm}$ (Schröder et al., 1987). As frações retidas nas peneiras foram secas e submetidas à análise densimétrica por flutuação-afundamento em tricloroetileno, visando separar os foraminíferos do sedimento (Scott et al., 2001).

Uma vez separadas, as carapaças dos foraminíferos, independente de tamanho, coloração ou grau de fragmentação, foram triadas, fixadas com goma adragante em lâminas quadriculadas de fundo escuro, identificadas e contadas. Algumas amostras que apresentaram número muito elevado de indivíduos foram subamostradas. Esta 


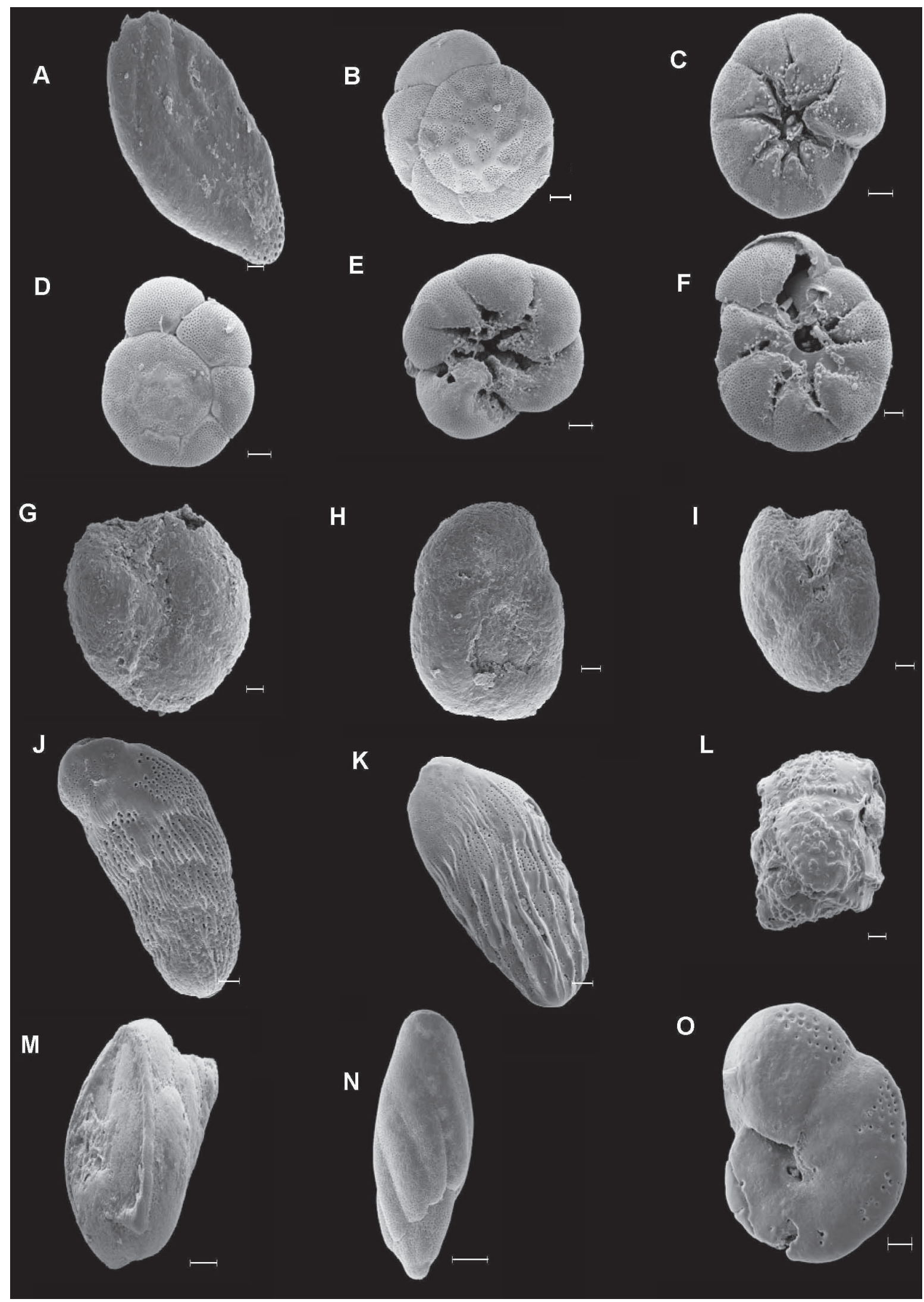

Figura 4. Foraminíferos do testemunho AR4: A, Ammoastuta salsa, 120-123 cm; B, Ammonia tepida, 120-123 cm; C, A. tepida, $120-123$ cm; D, A. tepida, 120-123 cm; E, A. tepida, 120-123 cm; F, A. tepida, 12-15 cm; G, Arenoparella mexicana, 22-25 cm; H, A. mexicana, $90-$ $93 \mathrm{~cm}$; I, A. mexicana, 90-93 cm; J, Bolivina sp., 251-254 cm; K, Brizalina striatula, 251-254 cm; L, Bulimina marginata, 261-264 cm; M B. marginata, 221-224 cm; N, Buliminella elegantissima, 251-254 cm; O, Cibicides sp., 251-254 cm. Escalas: A-I, M-O = $30 \mu \mathrm{m} ; \mathrm{J}-\mathrm{L}=20 \mu \mathrm{m}$ Figure 4. Foraminifera of the core AR4. Scale bars: A-I, M-O $=30 \mu \mathrm{m} ; \mathrm{J}-\mathrm{L}=20 \mu \mathrm{m}$ 


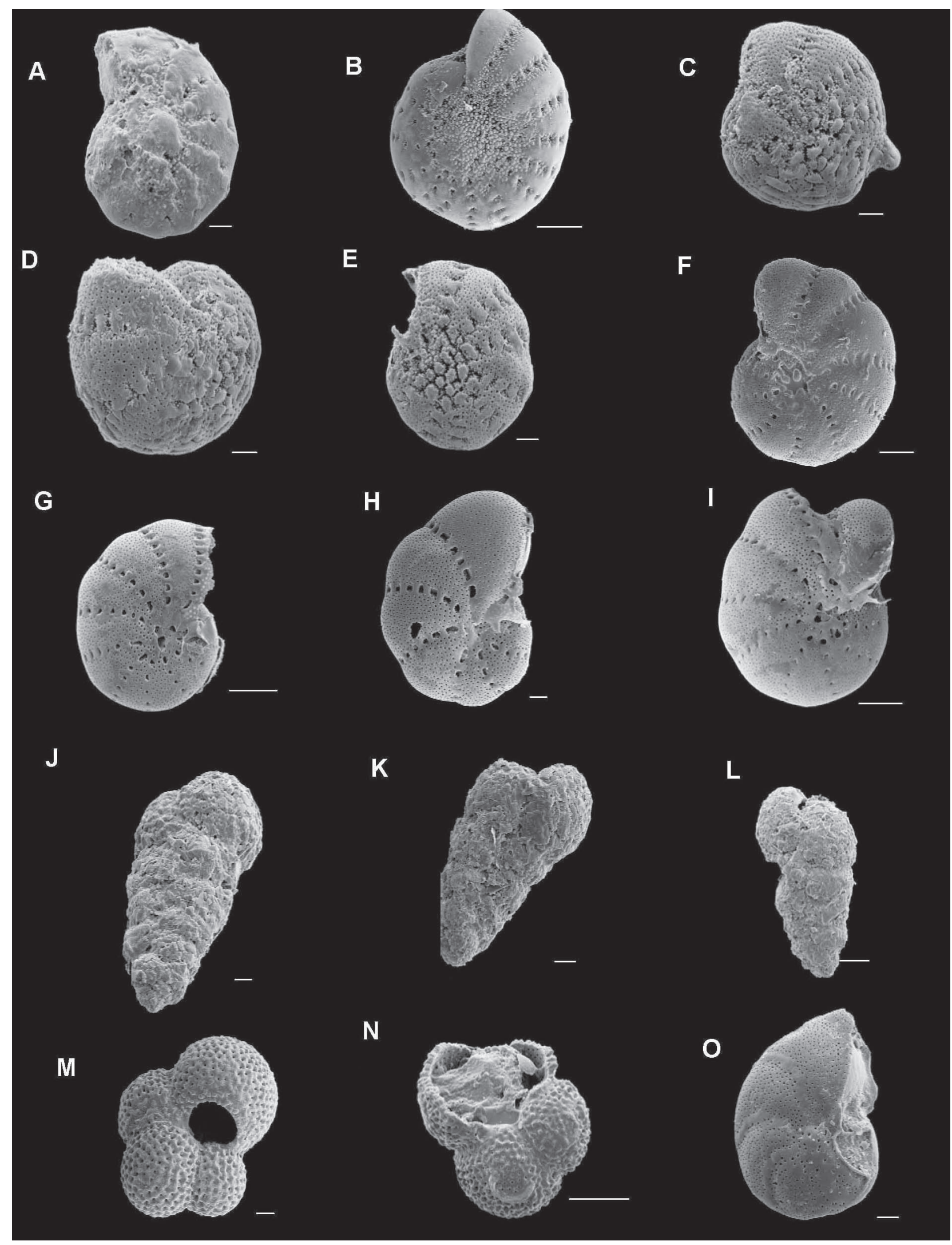

Figura 5. Foraminíferos do testemunho AR4. A, Cribroelphidium excavatum f. clavata, 251-254 cm; B, C. excavatum, $120-123 \mathrm{~cm}$; C, C. excavatum, 120-123 cm; D, C. excavatum, 120-123 cm; E, C. excavatum, 120-123 cm; F, C. poyeanum, 120-123 cm; G, C. poyeanum, $120-$ $123 \mathrm{~cm}$; H, C. poyeanum, 251-254 cm; I, C. poyeanum, 12-15 cm; J, Gaudryina exilis, 120-123 cm; K, G. exilis, 90-93 cm; L, G. exilis, $22-$ $25 \mathrm{~cm}$; M, Globigerina bulloides, 261-264 cm; N, Globigerina sp., 12-15 cm; O, Hanzawaia boueana, 261-264 cm. Escalas: A, B, D-F, H, $\mathrm{L}, \mathrm{M}, \mathrm{O}=30 \mu \mathrm{m} ; \mathrm{C}, \mathrm{G}, \mathrm{I}, \mathrm{J}, \mathrm{N}=100 \mu \mathrm{m} ; \mathrm{K}=20 \mu \mathrm{m}$.

Figure 5. Foraminifera of the core AR4. Scale bars: A, B, D-F, H, L, M, O = 30 $\mu \mathrm{m} ; \mathrm{C}, \mathrm{G}, \mathrm{I}, \mathrm{J}, \mathrm{N}=100 \mu \mathrm{m} ; \mathrm{K}=20 \mu \mathrm{m}$. 
Tabela 2. Dados geoquímicos do testemunho AR4.

Table 2. Geochemical data of the AR4 core.

\begin{tabular}{|c|c|c|c|c|c|c|c|c|c|}
\hline $\begin{array}{l}\text { Profundidade } \\
\quad(\mathrm{cm})\end{array}$ & & $\begin{array}{c}\mathrm{CaCO} 3 \\
(\%)\end{array}$ & $\begin{array}{c}\text { Corg. } \\
(\%)\end{array}$ & $\begin{array}{l}\text { Ntot. } \\
(\%)\end{array}$ & $\begin{array}{l}\text { Stot. } \\
(\%)\end{array}$ & $\mathrm{C} / \mathrm{N}$ & $\begin{array}{c}\text { Origem da matéria } \\
\text { orgânica (Bader,1955) }\end{array}$ & C/S & $\begin{array}{c}\text { Potencial de oxi-redução } \\
\text { sedimentos }\end{array}$ \\
\hline $00-05$ & 3,22 & Litoclástico & 0,295 & 0,025 & 0,062 & 11,817 & Mista & 4,748 & Tendência redutora \\
\hline $12-15$ & 3,7 & Litoclástico & 0,452 & 0,035 & 0,168 & 12,921 & Mista & 2,695 & Redutor \\
\hline $22-25$ & 3,78 & Litoclástico & 0,831 & 0,079 & 0,335 & 10,575 & Mista & 2,48 & Redutor \\
\hline $32-35$ & 2,97 & Litoclástico & 0,535 & 0,034 & 0,231 & 15,629 & Continental & 2,313 & Redutor \\
\hline $42-45$ & 2,27 & Litoclástico & 0,325 & 0,018 & 0,135 & 18,064 & Continental & 2,402 & Redutor \\
\hline $47-50$ & 2,52 & Litoclástico & 0,161 & 0,008 & 0,05 & 19,79 & Continental & 3,186 & Tendência redutora \\
\hline $50-53$ & 3 & Litoclástico & 0,329 & 0,018 & 0,116 & 18,325 & Continental & 2,843 & Redutor \\
\hline $60-63$ & 2,76 & Litoclástico & 0,218 & 0,011 & 0,067 & 20,004 & Continental & 3,267 & Tendência redutora \\
\hline $70-73$ & 8,14 & Litoclástico & 1,687 & 0,119 & 0,78 & 14,131 & Mista & 2,162 & Redutor \\
\hline $80-83$ & 10,24 & Litoclástico & 2,561 & 0,166 & 1,014 & 15,446 & Continental & 2,526 & Redutor \\
\hline $90-93$ & 5,77 & Litoclástico & 1,332 & 0,084 & 0,593 & 15,795 & Continental & 2,245 & Redutor \\
\hline $100-103$ & 4,29 & Litoclástico & 0,557 & 0,033 & 0,287 & 16,634 & Continental & 1,942 & Redutor \\
\hline $110-113$ & 3,59 & Litoclástico & 0,641 & 0,03 & 0,292 & 21,698 & Continental & 2,194 & Redutor \\
\hline $120-123$ & 4,46 & Litoclástico & 0,418 & 0,022 & 0,195 & 19,254 & Continental & 2,143 & Redutor \\
\hline $130-133$ & 5,65 & Litoclástico & 0,975 & 0,064 & 0,409 & 15,312 & Continental & 2,385 & Redutor \\
\hline $140-143$ & 1,94 & Litoclástico & 0,209 & 0,014 & 0,08 & 14,598 & Mista & 2,624 & Redutor \\
\hline $150-153$ & 2,83 & Litoclástico & 0,356 & 0,024 & 0,146 & 14,865 & Mista & 2,431 & Redutor \\
\hline $160-163$ & 3,56 & Litoclástico & 0,531 & 0,03 & 0,229 & 17,55 & Continental & 2,314 & Redutor \\
\hline $170-173$ & 4,63 & Litoclástico & 0,675 & 0,04 & 0,291 & 16,985 & Continental & 2,318 & Redutor \\
\hline $178-181$ & 5,58 & Litoclástico & 0,816 & 0,044 & 0,342 & 18,636 & Continental & 2,387 & Redutor \\
\hline $191-194$ & 4,6 & Litoclástico & 0,651 & 0,042 & 0,295 & 15,499 & Continental & 2,202 & Redutor \\
\hline $201-204$ & 3,95 & Litoclástico & 0,472 & 0,027 & 0,187 & 17,62 & Continental & 2,524 & Redutor \\
\hline $211-214$ & 6,12 & Litoclástico & 0,86 & 0,047 & 0,349 & 18,113 & Continental & 2,464 & Redutor \\
\hline $221-224$ & 5,02 & Litoclástico & 0,584 & 0,034 & 0,276 & 17,02 & Continental & 2,116 & Redutor \\
\hline $231-234$ & 5,38 & Litoclástico & 0,661 & 0,035 & 0,284 & 18,822 & Continental & 2,326 & Redutor \\
\hline $241-244$ & 5,23 & Litoclástico & 0,575 & 0,03 & 0,27 & 19,261 & Continental & 2,129 & Redutor \\
\hline $251-254$ & 4,34 & Litoclástico & 0,504 & 0,026 & 0,234 & 19,586 & Continental & 2,158 & Redutor \\
\hline $261-264$ & 3,28 & Litoclástico & 0,465 & 0,017 & 0,209 & 26,762 & Continental & 2,226 & Redutor \\
\hline $273-276$ & 4,04 & Litoclástico & 0,439 & 0,024 & 0,219 & 18,125 & Continental & 2,005 & Redutor \\
\hline $276-279$ & 4,27 & Litoclástico & 0,287 & 0,014 & 0,12 & 20,901 & Continental & 2,399 & Redutor \\
\hline $288-291$ & 1,72 & Litoclástico & 0,094 & 0,004 & 0,028 & 25,117 & Continental & 3,377 & Tendência redutora \\
\hline $291-294$ & 1,44 & Litoclástico & 0,105 & 0,003 & 0,021 & 38,571 & Continental & 5,033 & Oxidante \\
\hline $301-304$ & 2,87 & Litoclástico & 0,215 & 0,009 & 0,076 & 23,667 & Continental & 2,84 & Redutor \\
\hline $311-314$ & 1,59 & Litoclástico & 0,084 & 0,003 & 0,019 & 26,946 & Continental & 4,313 & Tendência redutora \\
\hline $321-324$ & 2,22 & Litoclástico & 0,164 & 0,006 & 0,05 & 25,286 & Continental & 3,261 & Tendência redutora \\
\hline $331-334$ & 2,85 & Litoclástico & 0,304 & 0,014 & 0,107 & 22,233 & Continental & 2,836 & Redutor \\
\hline $341-344$ & 2,6 & Litoclástico & 0,295 & 0,013 & 0,137 & 22,141 & Continental & 2,151 & Redutor \\
\hline $350-353$ & 2,74 & Litoclástico & 0,254 & 0,011 & 0,113 & 23,592 & Continental & 2,24 & Redutor \\
\hline $353-356$ & 5,03 & Litoclástico & 0,792 & 0,041 & 0,415 & 19,392 & Continental & 1,911 & Redutor \\
\hline $363-366$ & 3,44 & Litoclástico & 0,428 & 0,022 & 0,244 & 19,848 & Continental & 1,757 & Redutor \\
\hline $373-376$ & 4,15 & Litoclástico & 0,538 & 0,028 & 0,28 & 19,271 & Continental & 1,923 & Redutor \\
\hline $383-386$ & 4,19 & Litoclástico & 0,603 & 0,031 & 0,302 & 19,231 & Continental & 2 & Redutor \\
\hline $393-396$ & 3,28 & Litoclástico & 0,331 & 0,039 & 0,163 & 8,462 & Mista & 2,032 & Redutor \\
\hline $403-406$ & 6,11 & Litoclástico & 0,635 & 0,034 & 0,344 & 18,794 & Continental & 1,847 & Redutor \\
\hline $413-416$ & 6,76 & Litoclástico & 0,811 & 0,043 & 0,445 & 18,726 & Continental & 1,825 & Redutor \\
\hline $423-426$ & 2,47 & Litoclástico & 0,371 & 0,018 & 0,161 & 20,836 & Continental & 2,31 & Redutor \\
\hline $429-432$ & 4,34 & Litoclástico & 0,706 & 0,036 & 0,324 & 19,742 & Continental & 2,178 & Redutor \\
\hline
\end{tabular}

subamostragem consistiu em homogeneizar, com auxílio de um pincel, o material decantado em placa de petri, dividindoo em partes iguais até a redução de 200 carapaças.

A classificação genérica dos foraminíferos seguiu Loeblich \& Tappan $(1964,1988)$. A identificação das espécies teve como referência imagens digitais de trabalhos realizados na região de Cananéia (Duleba, 1997), o banco de imagens do
Laboratório de Micropaleontologia da USP e por análises comparativas com exemplares pertencentes à coleção de micropaleontologia do IGc/USP.

Após a classificação taxonômica, foram elaborados gráficos de densidade e de riqueza das espécies. Baseandose em Duleba et al. (2005), as espécies identificadas foram separadas em grupos, como segue: foraminíferos aglutinantes 


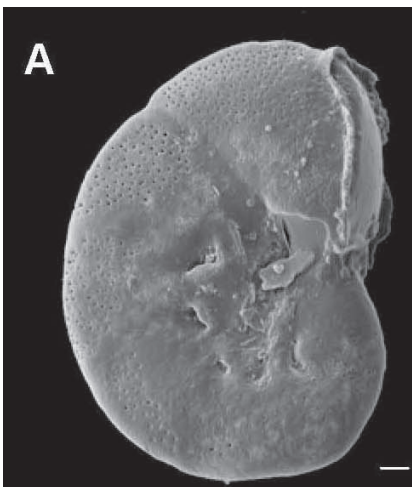

D

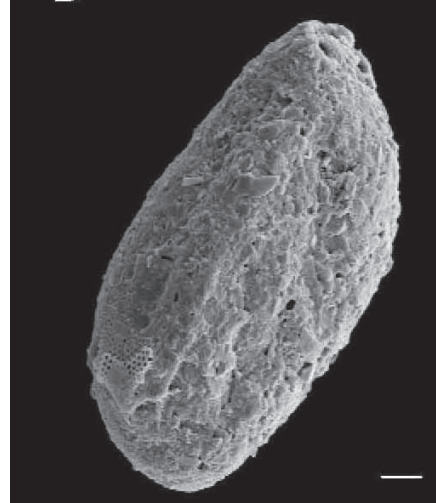

G
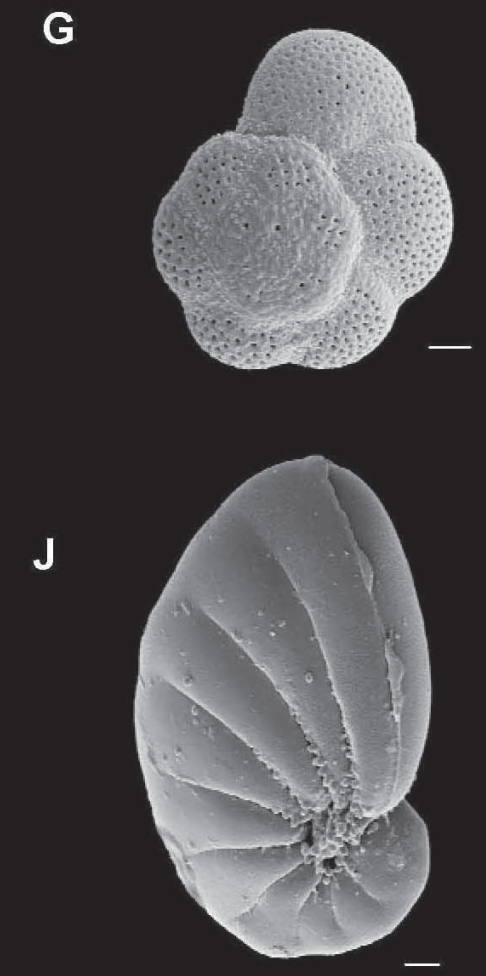

B

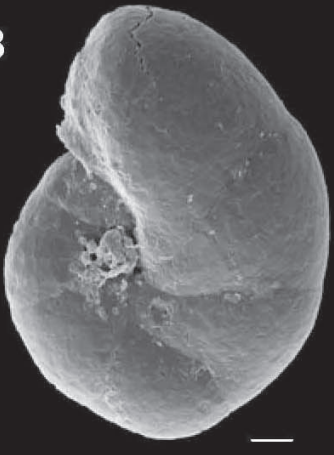

E

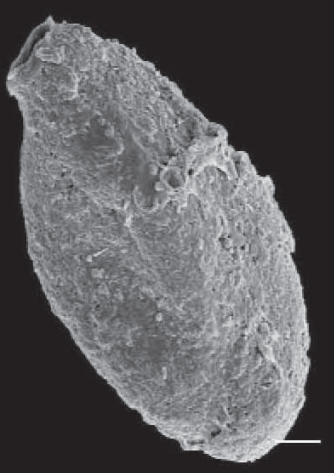

H

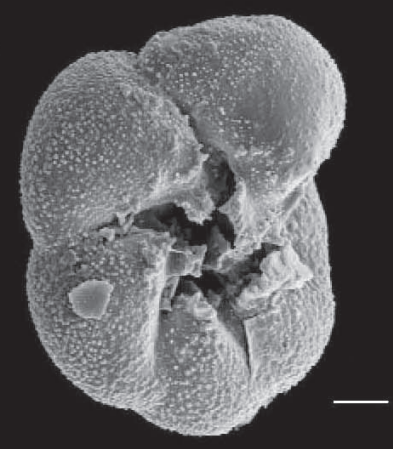

K

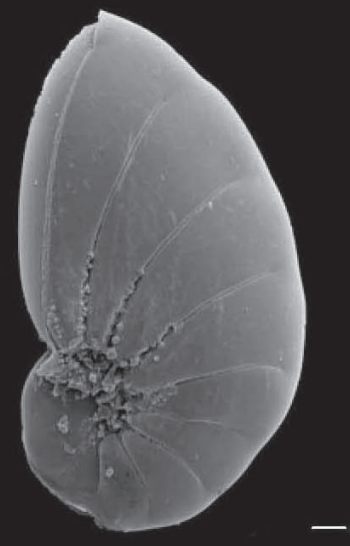

C

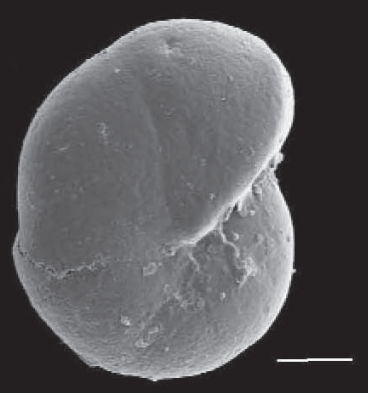

F

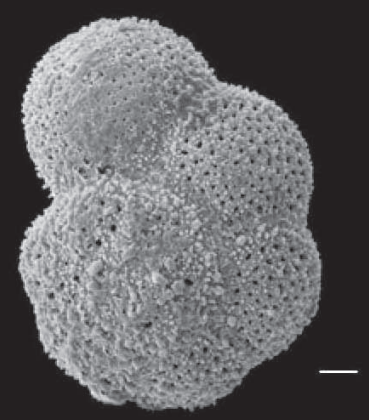

I

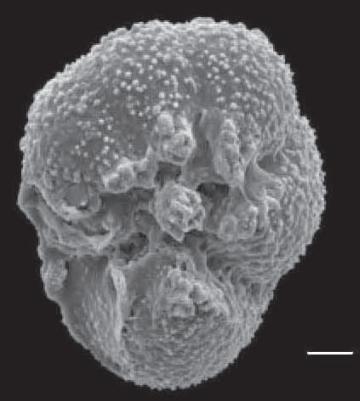

$\mathbf{L}$

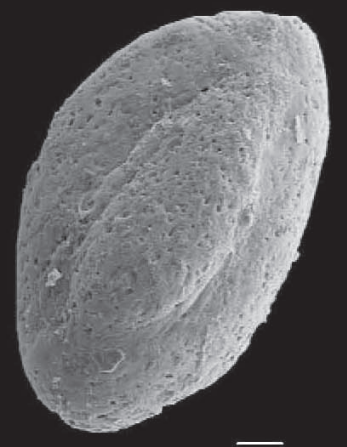

Figura 6. Foraminíferos do testemunho AR4. A, Hanzawaia boueana, 12-15 cm; B, Haplophragmoides wilberti, $22-25 \mathrm{~cm}$; C, Haplophragmoides wilberti, 12-15 cm; D, Miliammina fusca, 90-93 cm; E, Miliammina earlandi, 12-15 cm; F, Pararotalia cananeiaensis, 251-254 cm; G, Pararotalia cananeiaensis, 251-254 cm; H, Pararotalia cananeiaensis, 251-254 cm; I, Pararotalia cananeiaensis, 251$254 \mathrm{~cm}$; J, Pseudononion atlanticum, 251-254 cm; K, Pseudononion atlanticum, 221-224 cm; L, Quinqueloculina seminulum, 221-224 cm. Escalas: A, D, G $=20 \mu \mathrm{m} ; \mathrm{B}, \mathrm{E}, \mathrm{F}, \mathrm{H}-\mathrm{L}=30 \mu \mathrm{m} ; \mathrm{C}=100 \mu \mathrm{m}$.

Figure 6. Foraminifera of the core AR4. Scale bars: A, D, G $=20 \mu \mathrm{m} ; \mathrm{B}, \mathrm{E}, \mathrm{F}, \mathrm{H}-\mathrm{L}=30 \mu \mathrm{m} ; \mathrm{C}=100 \mu \mathrm{m}$. 
típicos de ambiente parálico, calcários mixoalinos e calcários marinhos típicos de plataformas interna e/ou externa.

Posteriormente, todas as carapaças triadas foram fotografadas em câmara digital acoplada em microscópio estereoscópico. A partir das imagens digitais foram realizadas análises morfométricas, utilizando-se $\mathrm{o}$ analisador de imagens Analysis. Carapaças foram agrupadas em pequenas $(<125$ $\mu \mathrm{m})$, médias $(125-250 \mu \mathrm{m})$, grandes $(250-500 \mu \mathrm{m})$ e muito grandes $(>500 \mu \mathrm{m})$, de acordo com Lançone et al.(2005). As fotografias das figuras 5-6 foram tomadas em MEV.

\section{RESULTADOS}

\section{Descrição macroscópica}

O testemunho AR4 apresenta 4,32 $\mathrm{m}$ de comprimento (Figura 2). Sua porção basal (432 a $353 \mathrm{~cm}$ de profundidade) é constituída por sedimentos arenosos cinza-esverdeados, fortemente bioturbados, com várias intercalações milimétricas a centimétricas de lama cinza escura e fragmentos vegetais. A partir de $353 \mathrm{~cm}$, a porção basal é sobreposta, em contato gradacional, por um intervalo arenoso fino, com lentes milimétricas de lama, que se prolonga até $290 \mathrm{~cm}$ de profundidade. Esse intervalo apresenta vários fragmentos vegetais dispersos que tendem a aumentar rumo ao topo do testemunho.

De 290 a $276 \mathrm{~cm}$ de profundidade, também em contato gradacional, passa a ocorrer um intervalo arenoso fino maciço, sem material biogênico. Sobrepostos a ele, são observados, entre 276 a $181 \mathrm{~cm}$ de profundidade, sedimentos arenolamosos, com vários fragmentos biogênicos com predominância de conchas de moluscos.

De 181 a $143 \mathrm{~cm}$ de profundidade, sobrepõem-se, em contato gradacional com a porção inferior, sedimentos arenosos finos, com lentes centimétricas de lama, bioturbação escassa e fragmentos vegetais dispersos. De 143 a $63 \mathrm{~cm}$ de profundidade, passam a ocorrer vários fragmentos de moluscos e vegetais. De 63 a $50 \mathrm{~cm}$ de profundidade, surgem intercalações centimétricas de areia com milimétrica de lama na matriz arenosa. De $50 \mathrm{~cm}$ ao topo, passa a ocorrer, em contato gradacional com o intervalo anterior, uma seqüência arenosa maciça sem componentes biogênicos.

\section{Análises granulométricas e radiométricas $\left({ }^{14} \mathrm{C}\right)$}

O testemunho AR4 é composto essencialmente por areia fina, com diâmetro médio de 2,4 a $3 \phi$ (Figura 3, Tabela 1). As porcentagens de areia variam de 85 a $100 \%$. Nas porções onde ocorrem camadas milimétricas a centimétricas de lama e porções com intercalações areno-lamosas, nota-se a diminuição na porcentagem de areia (Figura 3, Tabela 1). Da base até $291 \mathrm{~cm}$ de profundidade, constata-se granocrescência ascendente (Figura 3, Tabela 1). A partir de 291 até a profundidade de $183 \mathrm{~cm}$ passa a ocorrer granodecrescência, devido ao aumento das porcentagens de lama (Figura 3, Tabela 1). Rumo ao topo, são observadas granocrescências nos intervalos entre 183 a $143 \mathrm{~cm}$ e de 50 $\mathrm{cm}$ ao topo. Entre estes dois intervalos (i.e, no intervalo de
143 a $53 \mathrm{~cm}$ ) ocorre aumento das porcentagens de lama (Tabela 1).

A concha amostrada na profundidade de $348 \mathrm{~cm}$ forneceu a idade de $5010 \pm 40$ anos AP (idade calibrada de 5455 a 5280 anos AP) (Figura 3). A idade obtida para o fragmento vegetal coletado entre as profundidades de 288 e $291 \mathrm{~cm}$ indicou $4650 \pm 40$ anos AP (idade calibrada de 5465 a 5295 anos AP). A concha amostrada entre as profundidades de 181 a $178 \mathrm{~cm}$ forneceu a idade de 860 \pm 40 anos AP (idade calibrada de 530 a 435 anos AP). O fragmento vegetal coletado entre a profundidade de 80 a $83 \mathrm{~cm}$ foi datado em $180 \pm 40$ anos AP (idade calibrada de 235 a 65 anos AP).

\section{Análises geoquímicas}

Os resultados dos teores de carbonato de cálcio indicam a ocorrência de areia litoclástica em todos os intervalos. Quanto aos demais resultados geoquímicos, estes indicam diminuição progressiva do aporte de carbono orgânico, nitrogênio e enxofre totais, da base até a profundidade de $288 \mathrm{~cm}$, onde foi observado $100 \%$ de areia (Figura 3). De $288 \mathrm{~cm}$ até $183 \mathrm{~cm}$ houve aumento na quantidade destes elementos, juntamente com a diminuição da porcentagem de areia. A partir de $183 \mathrm{~cm}$, esses valores aumentam significativamente, chegando à concentração máxima na profundidade de $83 \mathrm{~cm}$ (Figura 3 , Tabela 2). De $83 \mathrm{~cm}$ até o topo, eles voltam a diminuir progressivamente, concomitantemente ao aumento das porcentagens de areia.

Os valores das razões $\mathrm{C} / \mathrm{N}$ indicam que a origem da matéria orgânica (M.O.) do testemunho AR4 é quase exclusivamente continental. Somente nas profundidades de 393, 153, 140 e $70 \mathrm{~cm}$, e no topo do testemunho, é que os valores da razão $\mathrm{C} / \mathrm{N}$ são sugestivos de origem mista (Tabela 2). Quanto à razão $\mathrm{C} / \mathrm{S}$, constata-se que a maioria dos sedimentos analisados foi depositada sob condição redutora, excetuando-se os sedimentos do intervalo entre 324 e $290 \mathrm{~cm}$, que apresentam condições mais oxidantes (Tabela 2).

\section{Análises microfaunísticas}

Foram identificadas 34 espécies de foraminíferos (Tabela 3). Algumas destas espécies são mostradas nas figuras 4-6. Os valores de densidade variam de 0 a 1200 indivíduos. $10 \mathrm{cc}^{-1}$, os mais altos estando concentrados no intervalo de 288 a 100 $\mathrm{cm}$. Os valores de riqueza variam entre 0 e 16 espécies e os maiores valores se concentram na profundidade entre 288 a $170 \mathrm{~cm}$ (Figura 3). De 426 a $288 \mathrm{~cm}$ de profundidade são observadas somente diatomáceas e muitos fragmentos de vegetais vasculares, com ocorrência episódica de foraminíferos calcários marinhos entre 334-331 cm (Tabela 3). A partir de $279 \mathrm{~cm}$, os foraminíferos são abundantes, ocorrendo cerca de 600 espécimes. $10 \mathrm{cc}^{-1}$ distribuídos entre mais de 10 espécies, com a predominância de Pararotalia cananeiaensis, um foraminífero típico de plataforma interna (Figuras 6 e 7). Na profundidade de 163 a $160 \mathrm{~cm}$, predominam os foraminíferos calcários mixohalinos e 
A. Pararotalia cananeiaensis
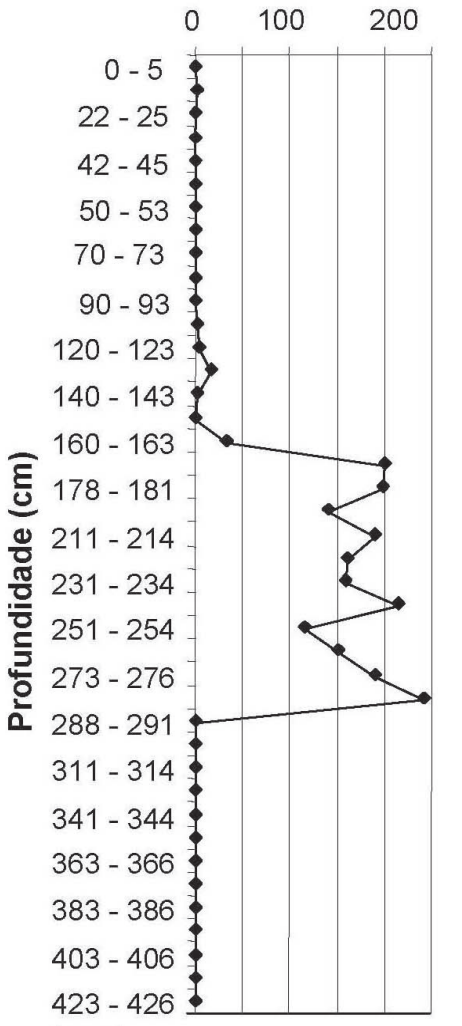

E Arenoparrela mexicana

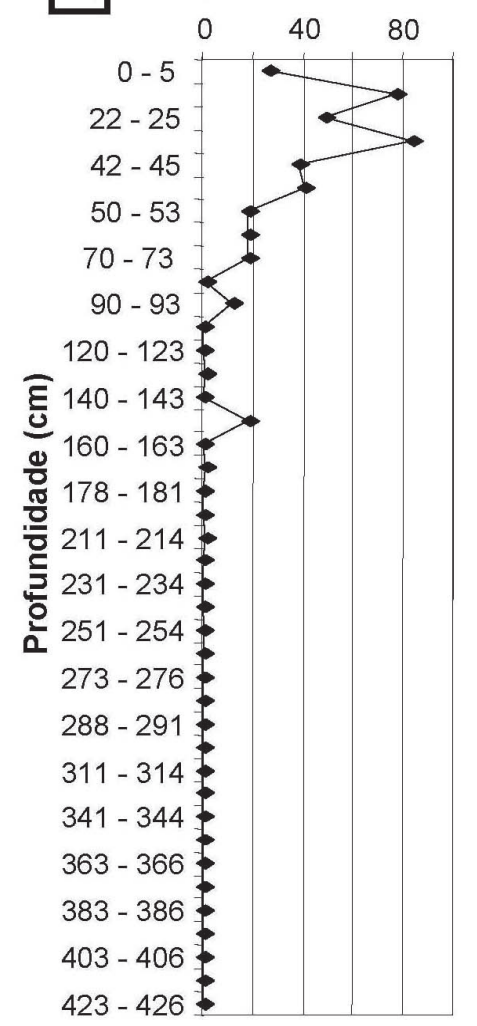

Discorbis williamsoni Hanzawaia boueana
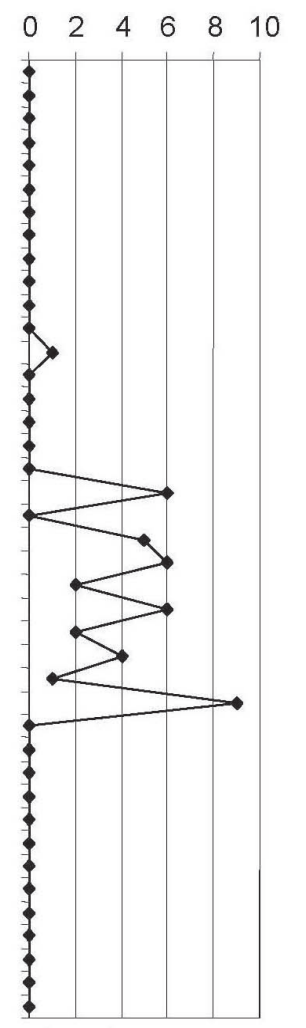

F Haplophragmoides wilberti

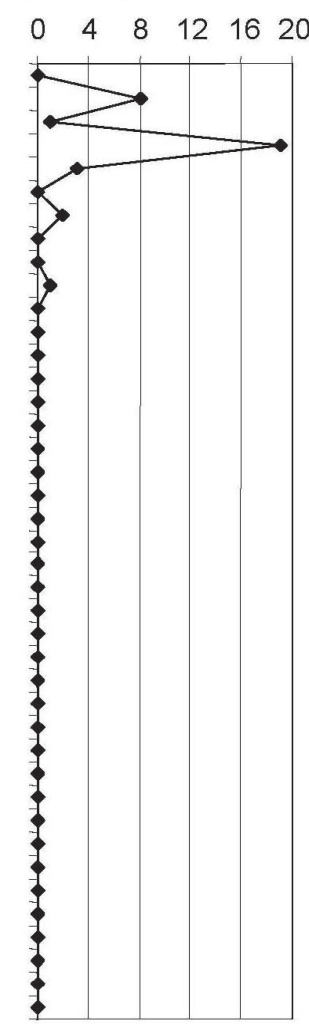

C. Ammonia tepida

D $\begin{aligned} & \text { Cribroelphidium } \\ & \text { excavatum }\end{aligned}$

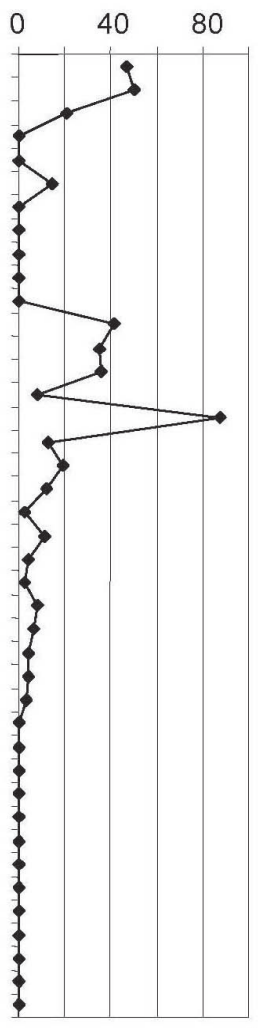

$0 \quad 100 \quad 200$

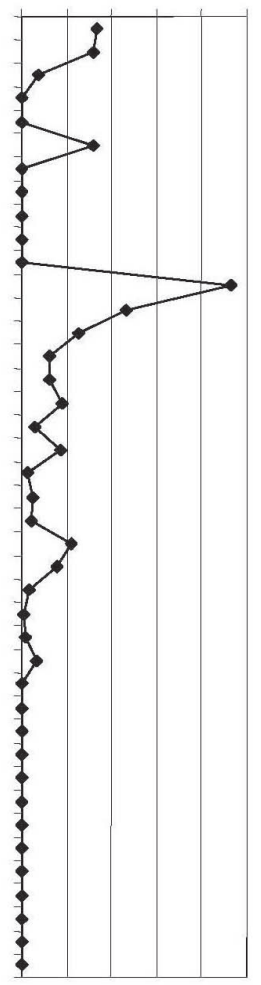

G Milammina spp.
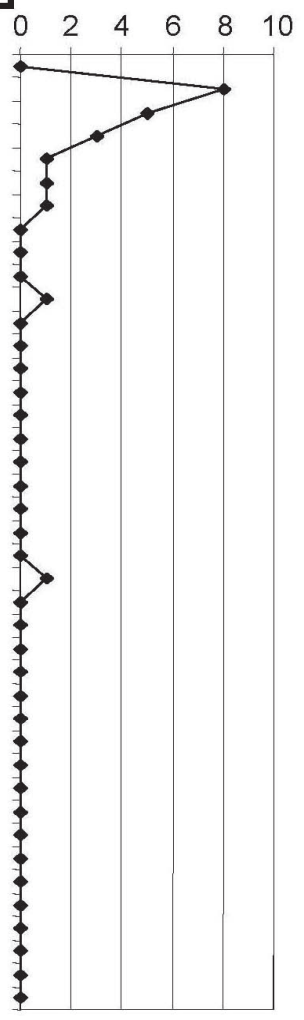

Figura 7. Freqüência absoluta de foraminíferos ao longo do testemunho AR4. A-B, espécies calcárias marinhas; C-D, espécies calcárias mixohalinas; E-F, espécies aglutinantes de ambiente estuarino confinado (canal ou mangue); G, espécie aglutinante salobra.

Figure 7. Absolute frequency of foraminifers along the core AR4. A-B, marine calcareous species; C-D, mixohaline calcareous species; E-F, confined environment agglutinated species (channel or mangrove); G, brackish agglutinated species. 
calcários marinhos de plataforma interna. De 153 a $150 \mathrm{~cm}$ de profundidade para o topo, predominam os foraminíferos tipicamente mixohalinos. De 93 a $50 \mathrm{~cm}$ de profundidade, os valores de densidade e riqueza diminuem consideravelmente, com o predomínio de foraminíferos aglutinantes de ambiente parálico. De $50 \mathrm{~cm}$ até o topo, os valores de densidade e riqueza de espécies aumentam, com o predomínio de foraminíferos aglutinantes e calcários mixohalinos. Em resumo, constata-se que a partir de $288 \mathrm{~cm}$ para o topo ocorre uma sucessão de assembléias iniciada por foraminíferos calcários marinhos de plataforma interna, passando para foraminíferos calcários mixohalinos e finalmente para foraminíferos aglutinantes típicos de manguezal.

\section{DISCUSSÃO}

Excetuando-se a profundidade de 331 a $334 \mathrm{~cm}$, onde foram encontradas somente três testas de foraminíferos, a porção inferior do testemunho (i.e., 423 a $279 \mathrm{~cm}$ de profundidade) é constituída por sedimentos arenosos finos litoclásticos, com baixas porcentagens de $\mathrm{C}, \mathrm{N}$ e $\mathrm{S}$, com matéria orgânica de origem continental, redutores (excetuando o intervalo compreendido entre 291 e $294 \mathrm{~cm}$, onde os sedimentos têm características oxidantes), ricos em diatomáceas e destituídos de foraminíferos. É possível que as três testas de foraminíferos acima referidas sejam alóctones, visto que apresentavam marcas de abrasão. Concha e fragmento vegetal, situados a 348 e $288 \mathrm{~cm}$ de profundidade, forneceram as idades de 5010 e $4650 \pm 40$ anos AP, respectivamente. Entre estes dois níveis temporais, a taxa de sedimentação foi de $0,147 \mathrm{~cm} \cdot a^{-1}$.

Segundo o esquema evolutivo da ilha Comprida de Martin \& Suguio (1978), durante o máximo da Transgressão Santos (5100 anos AP), a parte sul da ilha estaria submersa pelo mar. Ainda segundo estes autores, após este nível máximo, iniciouse período regressivo, que propiciou a formação de vários depósitos marinhos holocênicos, constituídos pelas areias erodidas pela transgressão. Portanto, a porção inferior do testemunho do Arrozal provavelmente corresponderia a esses depósitos arenosos.

Somente a partir de $288 \mathrm{~cm}$ de profundidade é que os foraminíferos passam a ocorrer em grande quantidade. Estes organismos são abundantes de 288 a $178 \mathrm{~cm}$ de profundidade. Concomitante ao aparecimento dos foraminíferos, constatou-se diminuição da porcentagem de areia, aumento do aporte de carbono orgânico, nitrogênio e enxofre. A origem da M.O. continua sendo continental e os sedimentos apresentam forte tendência redutora. Pelo gráfico da figura 2, as maiores concentrações de foraminíferos estão associadas a sedimentos mais finos. De acordo com Boltovskoy \& Wright (1976), a abundância de testas de foraminíferos é inversamente proporcional ao tamanho dos grãos dos sedimentos, ou seja, sedimentos mais finos propiciam a proliferação destes organismos. Essa concentração de testas também deve estar relacionada à baixa taxa de sedimentação que ocorreu entre 288 e 178 cm de profundidade $\left(0,03 \mathrm{~cm} \cdot \mathrm{ano}^{-1}\right)$.

No intervalo de 288 a $178 \mathrm{~cm}$, em que Pararotalia cananeiaensis é dominante, as espécies de foraminíferos são típicas de ambiente de plataformal interno (e.g., Hanzawaia boueana, Pseudononion atlanticum), ocorrendo, inclusive, Globigerina bulloides e Uvigerina bifurcata, próprias de meio mais distal (Figura 5L). Particularmente estas duas últimas espécies devem ter sido transportadas por correntes. A presença de organismos tipicamente marinhos permite inferir forte influência marinha no local do testemunho do Arrozal, entre aproximadamente 4650 e 860 anos A.P. Uma hipótese plausível para a presença destes organismos de plataforma seria que neste período o tamanho da ilha Comprida era menor que o atual. Ou seja, sem a presença de anteparo, a influência marinha era mais franca no local onde hoje se situa o Arrozal. A desembocadura de Cananéia deveria estar mais próxima da região do Arrozal. Esta interpretação é coerente com o modelo de Suguio \& Martin (1978), pois segundo estes autores, à medida que o nível do mar abaixava na região de Cananéia (após a Transgressão Santos, 5100 anos A.P.), ocorria adição de várias cristas praiais, o que resultou no "crescimento" da ilha Comprida para o norte, rumo a Iguape, deixando a parte sul mais exposta à influência marinha.

A partir de $153 \mathrm{~cm}$ de profundidade, os foraminíferos calcários mixohalinos (Cribroelphidium excavatum s.l. e Ammonia tepida) e os aglutinantes (Arenoparella mexicana, Haplophragmoides wilberti) tornam-se mais abundantes que os marinhos (Figura 5). As duas primeiras espécies são mais abundantes que as espécies aglutinantes, isto indica ocorrência de ambiente estuarino/lagunar associado a manguezais. Durante esse período, supõe-se que grande parte da ilha Comprida já teria sido formada, agindo como anteparo natural à entrada do mar.

De 143 a $12 \mathrm{~cm}$ de profundidade, os aglutinantes aumentam progressivamente rumo ao topo, sugerindo a presença de manguezais. A presença de Miliammina fusca indica maior aporte de água doce entrando no sistema (Figura 5).

No topo do testemunho, a presença de calcários mixohalinos em associação com aglutinantes, volta a ser abundante, sugerindo ambiente de borda de manguezal com influência marinha moderada.

\section{CONCLUSÕES}

As variações na composição de espécies de foraminíferos encontradas ao longo de parte do testemunho AR4, avaliadas em conjunto com as análises sedimentológicas e geoquímicas, permitiram detectar mudanças ambientais significativas na região do Arrozal nos últimos 5000 anos.

O local sofreu forte influência marinha entre $<4650$ e 860 anos A.P., período em que apresentou microfauna com características de ambiente marinho costeiro. Posteriormente, o nível do mar tornou-se mais baixo, a ilha Comprida estendeu-se rumo ao norte e a desembocadura de Cananéia deslocou-se mais para o sul. Assim, a região 
do Arrozal tornou-se progressivamente mais estuarina, havendo a implantação de manguezais há aproximadamente 180 anos A.P.

\section{AGRADECIMENTOS}

Os autores agradecem à A. C. Teodoro e J. B. Silva pelo inestimável auxílio em diversas etapas do desenvolvimento do trabalho; a J. D. Kirk e T. R. Fairchild pela revisão do abstract; e aos consultores ad hoc pelas valiosas sugestões e cuidadosa revisão do manuscrito.

\section{REFERÊNCIAS}

Angulo, R.J. \& Lessa, G.C. 1997. The Brazilian sea-level curves: a critical review with emphasis on the curves from the Paranaguá and Cananéia regions. Marine Geology, 140:141-166.

Angulo, R.J.; Lessa, G.C. \& Souza, M.C. 2006. A critical review of mid- to late-Holocene sea level fluctuations on the eastern Brazilian coastline. Quaternary Science Reviews, 25:486506.

Almeida, F.F.M de \& Carneiro, C. R. 1998. Origem e evolução da Serra do Mar. Revista Brasileira de Geociências, 28(2):135150.

Bader, R.G. 1955. Carbon and nitrogen relations in suface and subsurface marine sediments. Geochimica Cosmochimica Acta, 7(5/6):205-211.

Boltovskoy, E. \& Wright, R. 1976. Recent Foraminifera. $1^{\mathrm{a}} \mathrm{ed}$. The Hague, W. Junk. Publishers, 515 p.

Bonetti, C.V.H.C. 1995. Associações de foraminiferos e tecamebas indicadoras de sub-ambientes recentes na zona estuarina do rio Itapitangui - Cananéia/SP. Programa de Pós-graduação em Oceanografia Biológica, Universidade de São Paulo, Dissertação de Mestrado, 150 p.

Borrego, J.; Lopez, M.; Pedon, J.G. \& Morales, J.A. 1998. C/S ratios in estuarine sediments of the Odiel River-mouth, S.W. Spain. Journal of Coastal Research, 14(4):1276-1283.

Debenay, J.P.; Eichler, B.B.; Duleba, W.; Bonetti, C. \& EichlerCoelho, P.P.B. 1998. Stratification of waters in coastal lagoons: it's influence on foraminiferal assemblages in two Brazilian lagoons. Marine Micropaleontology, 35:67-89.

Duleba, W. 1997. Variações nas associações de tecamebas, foraminiferos e ostracodes sub-recentes da região lagunar de Cananéia-Iguape, SP. Programa de Pós-graduação em Oceanografia Biológica, Universidade de São Paulo, Tese de Doutorado, $224 \mathrm{p}$.

Duleba, W.; Coimbra, J.C.S.; Petri, S. \& Barbosa, C.F. 2005. Foraminíferos, tecamebas e ostracodes recentes utilizados como bioindicadores em estudos ambientais brasileiros. In : C.R.G. Souza, K. Suguio, A.M.S. Oliveira \& P.E. Oliveira (eds.) Quaternário do Brasil, Editora Holos, p. 176-201.

Eichler, B.B \& Bonetti, C.V.C. 1995. Distribuição dos foraminíferos e tecamebas ocorrentes no manguezal do rio Baguaçu, Cananéia, São Paulo - relações com alguns parâmetros ambientais. Pesquisas, 22(1/2):32-37.

Eichler, B.B.; Debenay, J.P.; Bonetti, C.V.C. \& Duleba, W. 1995. Repartition des foraminifères benthiques dans la zone Sud-Oest du systéme lagunar-estuarien, d'Iguape-Cananéia (Brésil). Boletim do Instituto Oceanográfico da USP, 43(1):1-17.

Eichler-Coelho, P.P.B.; Duleba, W; Eichler, B.B \& Coelho-Jr., C.
1997. Determinação do impacto ecológico do Valo Grande (Iguape), a partir das associações de foraminíferos e tecamebas. Revista Brasileira de Biologia, 57(3): 463-477.

Gross, M.D. 1971. Carbon determination. In: R.E. Carver (ed.) Procedures in sedimentary petrology, Wiley-Interscience, $\mathrm{p}$. 573-596.

Lançone, R.B.; Duleba, W. \& Mahiques, M.M. 2005. Circulação hidrodinâmica da Enseada do Flamengo, Ubatuba, SP, inferida a partir da distribuição espacial e morfometria de foraminíferos. Revista Brasileira de Paleontologia, 8(3):181-192.

Larssoneur, C.; Bouysse, P. \& Aaufret, J.P. 1982. The superficial sediments of the English Channel and its Western Approaches. Sedimentology, 29(6): 851-864.

Loeblich, A.R. \& Tappan, H. 1964. Protista. In: R.C. Moore (ed.) Treatise on invertebrate paleontology, Part $C$. The University Kansas Press, 2v., 900 p.

Loeblich, A.R. \& Tappan, H. 1988. Foraminiferal genera and their classification. $1^{\mathrm{a}}$ ed. New York, Van Nostrand Reinhold, 2 v., 970 p.

Martin, L. \& Suguio, K. 1978. Ilha Comprida: um exemplo de ilhabarreira ligada às flutuações do nível marinho durante o Quaternário. In: CONGRESSO BRASILEIRO DE GEOLOGIA, 30, 1978. Anais, Recife, SBG, v.2, p. 905-912.

Petri, S. \& Lellis, H.S. 1971. Foraminíferos holocênicos de duas sondagens perfuradas na região de Iguape-Cananéia, Estado de São Paulo. In: CONGRESSO BRASILEIRO DE GEOLOGIA, 25, 1971. Resumos, São Paulo, SBG/Núcleo de São Paulo, p. 90.

Petri, S. \& Suguio, K. 1971. Some aspects of the Neo-Cenozoic sedimentation in the Cananéia-Iguape lagoonal region, São Paulo, Brazil. Estudos Sedimentológicos, 1:25-33.

Petri, S. \& Suguio, K. 1973. Stratigraphy of the Iguape-Cananéia lagoonal region sedimentary deposits, São Paulo State, Brazil. Part II- heavy minerals studies, microorganisms inventories and stratigraphical interpretations. Boletim do Instituto de Geociências da Universidade de São Paulo, 4:71-85.

Scott, D.B.; Medioli, F.S. \& Schafer; C.T. 2001. Monitoring in coastal environments using foraminifera and thecamoebian indicators. Cambridge, Cambridge University Press, 177 p.

Schröder, C.J.; Scott, D.B. \& Mediolli, F.S. 1987. Can smaller benthic foraminifera be ignored in paleoenvironmental analyses? Journal of Foraminiferal Research, 4:101-110.

Stein, R. 1991. Accumulation of organic carbon in marine sediments: results from the Deep Sea Drilling Project/Ocean Drilling Program (DSDP/ODP). In: S. Battacharji, G.M. Friedman, H.J. Neugebauer \& A. Seilacher (eds.) Lecture Notes in Earth Sciences, Springer-Verlag, p. 1-217.

Suguio, K. 1973. Introdução à Sedimentologia. $1^{\mathrm{a}}$ ed. São Paulo, Edgard Blücher/EDUSP, 317 p.

Suguio, K. \& Martin, L.1978. Formação quaternária marinha do litoral paulista e sul fluminense. In: INTERNATIONAL SYMPOSIUM ON COASTAL EVOLUTION IN THE QUATERNARY, 1, 1978. Special Publication, São Paulo, SBG/ USP, v.1, p. 1-55.

Suguio, K. \& Martin, L. 1987. Classificação de costas e evolução geológica das planícies litorâneas quaternárias do Sudeste e Sul do Brasil. In: SIMPÓSIO SOBRE ECOSSISTEMAS DA COSTA SUL E SUDESTE DO BRASIL, SÍNTESE DE CONHECIMENTOS, 1, 1987. Anais, Cananéia, ACIESP, v.1, p. 1-28.

Suguio, K.; Martin, L.; Bittencourt, A.C.S.P.; Dominguez, J.M.L.; Flexor, J.M. \& Azevedo, A.E. G. 1985. Flutuações do nível 
relativo do mar durante o Quaternário superior ao longo do litoral brasileiro e suas implicações na sedimentação costeira. Revista Brasileira de Geociências, 15:273-286.

Suguio, K. \& Petri, S. 1973. Stratigraphy of the Iguape-Cananéia lagoonal region sedimentary deposits, São Paulo, Brazil. Part I: field observations and grain size analysis. Boletim do Instituto de Geociências da Universidade de São Paulo, 4:1-20.

Tessler, M.G. 1982. Sedimentação atual na região lagunar de Cananéia-Iguape, estado de São Paulo. Programa de Pós-graduação em Geociências, Universidade de São Paulo, Dissertação de Mestrado, v.1, 110 p.
Tessler, M.G. \& Furtado, V.V. 1983. Dinâmica de sedimentação das feições de assoreamento da região lagunar Cananéia-Iguape, estado de São Paulo. Boletim do Instituto Oceanográfico, 32:117124.

Tessler, M.G. \& Mahiques, M.M. 1993. Utilization of coastal geomorphic features as indicators of longshore transport: examples of the southern coastal region of the State of São Paulo. Brazil. Journal of Coastal Research, 9:823-830.

Wentworth, C.K. 1922. A scale of grade and class terms for clastic sediments. Journal of Geology, 30(1):377-392.

Received in April, 2007; accepted in September, 2007. 